Research Article

\title{
While all Eyes Are Set on Delhi, Kolkata Sitting on Ticking Time Bomb of Air Pollution
}

\author{
Monalisha Sahu
}

Assistant Professor Public Health, All India Institute of Hygiene and Public Health, Kolkata. DOI: https://doi.org/10.24321/2394.6539.201904

I $\quad \mathbf{N} \quad \mathbf{F} \quad \mathbf{O}$

E-mail Id:

drmonalisha@outlook.com

Orcid Id:

https://orcid.org/0000-0002-4818-5994

How to cite this article:

Sahu M. While all Eyes Are Set on Delhi, Kolkata

Sitting on Ticking Time Bomb of Air Pollution. J

Adv Res Med Sci Tech 2019; 6(1\&2): 18-24.

Date of Submission: 2019-12-28

Date of Acceptance: 2020-01-17
$\begin{array}{llllllll}\mathbf{A} & \mathbf{B} & \mathbf{S} & \mathbf{T} & \mathbf{R} & \mathbf{A} & \mathbf{C} & \mathbf{T}\end{array}$

\begin{abstract}
The metropolitan city of Kolkata today is facing challenges of air pollution like never before. With high population density and relatively lower green cover, the city is at the verge of being a gas chamber with its $A Q I$ ranging between very poor to poor in winter months. Though the problem of air pollution is multifactorial in the city, major source is automobiles. Despite laws, vehicles older than 15 years and diesel run vehicles ply uninhibitedly in the city. Also, the energy generation through conventional thermal power plant systems, use of biofuels by the residents, rapid urbanisation leading to continuous construction activities and constant decrease in the number of trees have made the situation further worse. The measures taken by government are slow in pace and insufficient. Though the capital city of India is facing all burnt at the centre stage of pollution, air pollution in Kolkata is less talked about and a relatively neglected issue. Another worrisome fact is that the city has high level of PM 2.5 which can easily enter the blood through lungs. The resulting health issues from such high levels of pollution are rampant and worrisome. It is not an exaggeration to nickname the city as lung cancer capital of India because of rising number of cancer patients for which air pollution is a major contributor. If timely swift actions are not taken; it will be too late to control the genocide in making.
\end{abstract}

Keywords: Air Pollution, Kolkata, AQI, PM 2.5, Lung Cancer, Temperature Inversion

\section{Introduction}

Indian cities are among the world's worst polluted, when ranked by levels of particulate matter. ${ }^{1}$ Delhi tops the list as world's highest polluted city with Kolkata being fifth most polluted city worldwide as per the real-time air-quality ranking reports by System of Air Quality and Weather Forecasting and Research (SAFAR). ${ }^{2}$ Though Delhi is presently facing most of the negative spotlight for air pollution; it is a less known fact that, Kolkata has surpassed Delhi in many terms of pollution.

\section{Air Pollution in Kolkata}

The metropolitan city of Kolkata, is the capital city of the state of West Bengal and home to 4.5 million people, with the urban agglomeration, comprising the city and its suburbs, home to almost 14.1 million people. ${ }^{3}$ The city has been dubbed as one of the most unplanned, dusty and polluted cities in the world in past. ${ }^{4}$ The city is struggling in the grip of rising multi-pollutant crisis leading to exponential rise in air pollution levels in the past decades. The city residents breathe five times more of bad air than the 
recommended standards. ${ }^{5}$ What is more alarming is that its air quality index is declining at a faster pace than that of Delhi. The Air Quality Index (AQI) is a way to measure air pollution levels. It gives an estimate of quality and purity of air and so determines the possible health effects it will have on human health. Environmental protection agency (EPA) calculates the AQI for five major air pollutants regulated by the Clean Air Act: ground-level ozone, particle pollution (also known as particulate matter including PM10 and PM2.5), carbon monoxide, sulphur dioxide and nitrogen dioxide. The EPA has standardized national air quality standards for each of the pollutants to protect public health. Out of all ground-level ozone and airborne particles are the two pollutants that pose the greatest threat to human life and environment. An AQI of 0 to 50 is described as 'good', 51 to 100 'satisfactory', 101 to 200 'moderate', 201 to 300 'poor', 301 to 400 'very poor' and 401 to 500 'severe'. An AQI above 500 falls in the 'severe plus emergency' category. ${ }^{6}$ Anything above the 100-mark may cause breathing discomfort for people with lung and heart diseases.

City's official ambient air-quality monitoring has shown an exponential rise of 61 per cent particulate matter just in four years from 2010 to 2013 (Figure 1). The levels exceed standards by 2.7 times. Worrisome for the city is the fact that the AQI in the city is driven mostly by PM 2.5. PM 2.5 are particles having diameter $<2.5$ micrometres, such small particles can directly penetrate the lung tissues and enter into the blood stream. The noxious chemicals riding piggyback on the ultrafine PM 2.5 particles play havoc on human health. The $\mathrm{NO}_{2}$ levels in the city have also increased by 13 per cent during these four years (Figure 2). The current $\mathrm{NO}_{2}$ levels exceed standards by 1.8 times which is a substantial threat for ozone pollution. The air in Kolkata has high levels of carcinogens like benzo(a)pyrene, benzene, carbonyl, and the like which are harmful even in very small doses.

\section{Air-quality Monitoring in Kolkata}

As far as air-quality monitoring is considered, the city currently has only two automatic online monitors located at Victoria Memorial Station and Rabindra Bharati station. Apart from these, 17 manual air-quality monitoring stations have also been installed and are being maintained by West Bengal Pollution Control Board (WBPCB). ${ }^{7}$ Manual air-quality measuring stations are prone to manipulations and human errors and therefore not recommended by the National Green Tribunal and the Central Pollution Control Board (CPCB). Automatic air-quality monitoring station requires least human intervention thus adding a lot of credibility to live data. Though regular data on PM 2.5 levels are not available in all seasons but the average daily PM2.5 levels recorded at the American Consulate has been seen to be as high as $170 \mu \mathrm{g} / \mathrm{m}^{3}$ which is three times the daily standard of $60 \mu \mathrm{g} / \mathrm{m}^{3}$. A summary of PM 2.5 concentrations for the period of 1998 to 2016 for the city of Kolkata as reported by WPCB is presented below (Figure 1).

A representation of summary of city's satellite derived data of PM10 and SO2 data (on 24-hour basis) from 2013 to 2018 has been also been presented in the Figure 2.

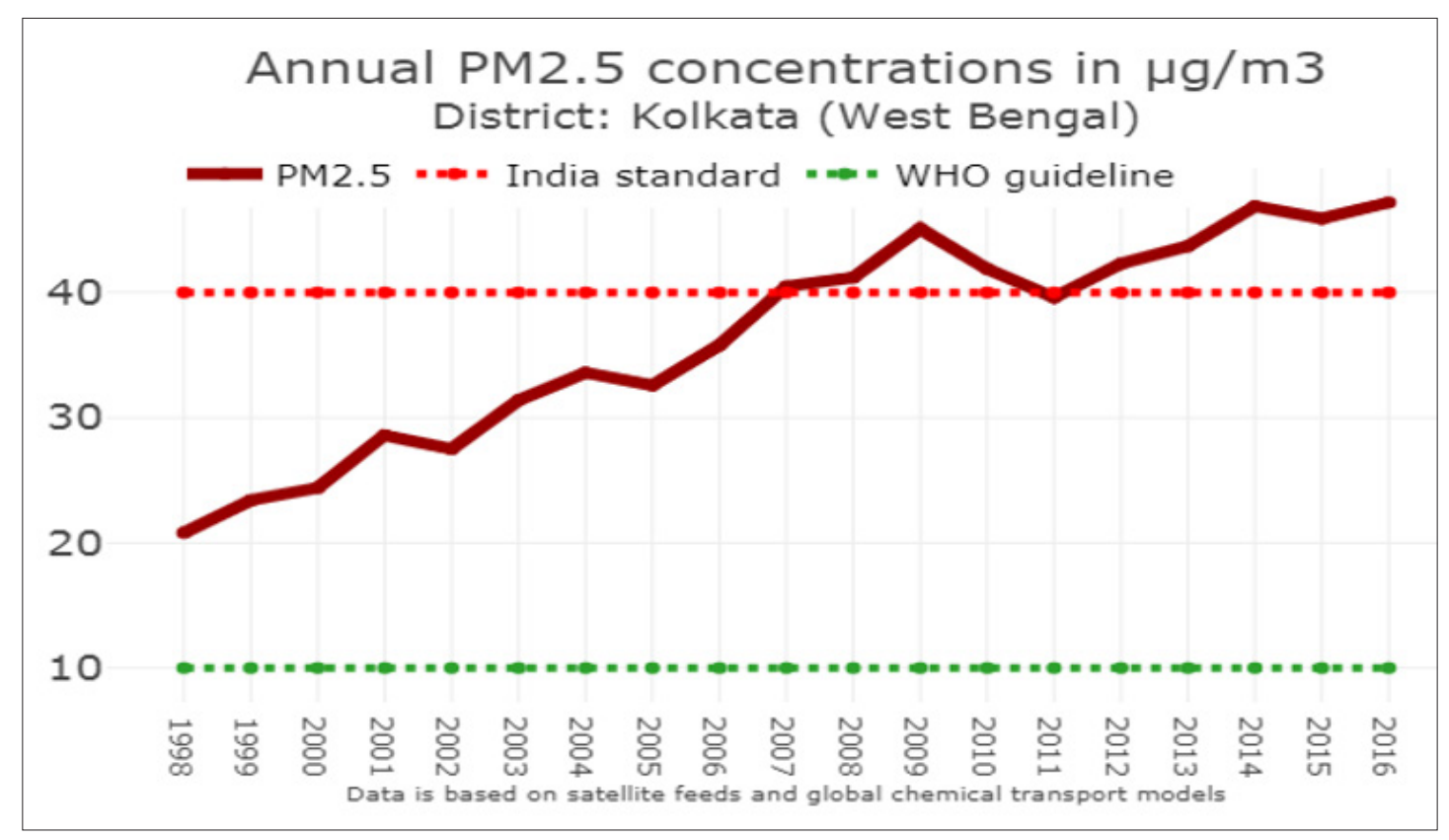

Figure I.The results of satellite data derived Surface PM2.5 Concentrations

[Source: West Bengal Pollution Control Board. Accessed from: http://www.wbpcb.gov.in/writereaddata/files/ comprehensive\%20air\%20quality\%20action\%20plan\%20(3).pdf] 


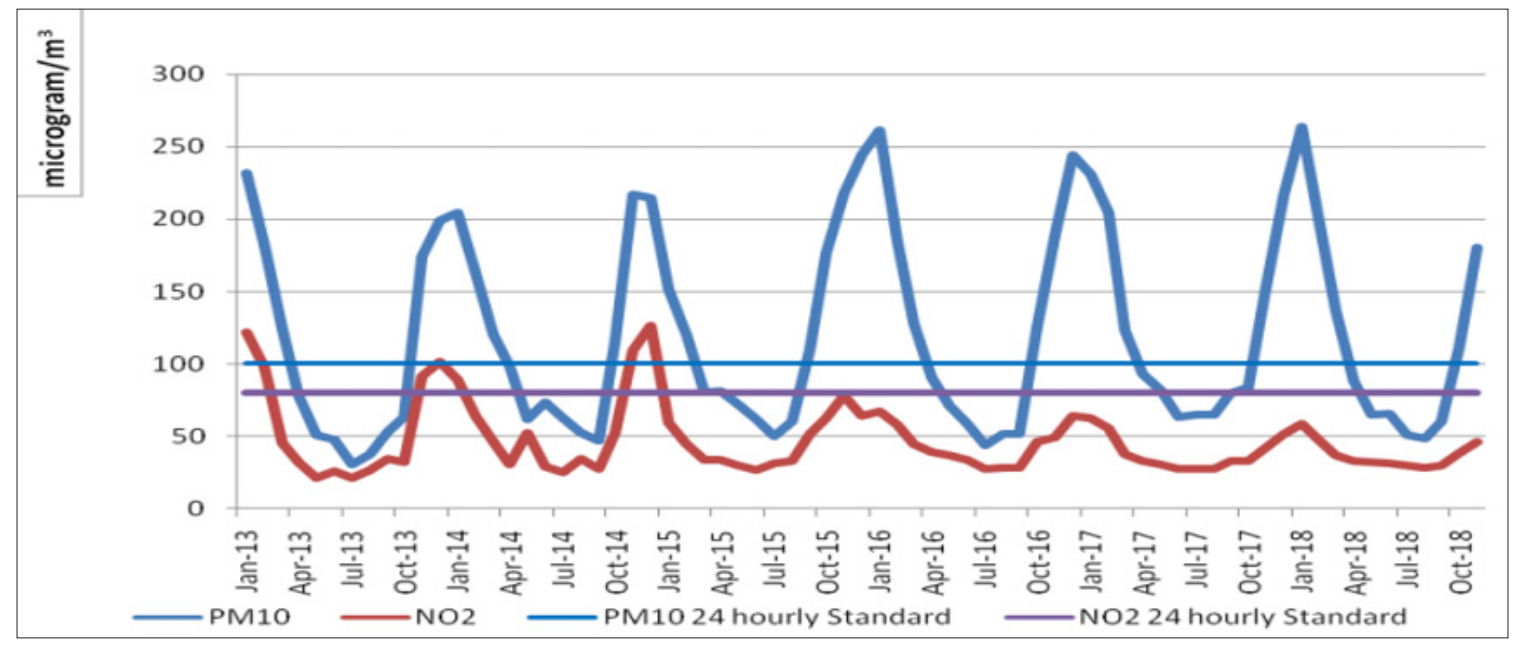

Figure 2.The results of satellite data derived Surface PM 10 and NO2 Concentrations

[Source:West Bengal Pollution Control Board. accessed from http://www.wbpcb.gov.in/writereaddata/files/ comprehensive\%20air\%20quality\%20action\%20plan\%20(3).pdf]

The PM10 data of city shows high night-time pollution. It has been reported that parts of south Kolkata like 'Gariahat, Mominpur and Hyde Road' have been seen to be exposed to higher pollution levels than the northern parts of the city. Pollution has also been reported pretty high at Minto Park and Moulali in central Kolkata. The Central Pollution Control Board has classified the following locations of cities as 'critically polluted' areas-Salt Lake, Moulali, Minto Park, Dunlop Bridge, Behala Chowrasta, Baishnabghata, Cossipore Police Station, B.T. Road, Dalhousie Square, Lal Bazzar Police Headquarter and Kasba. ${ }^{8}$

\section{Post-Diwali Kolkata}

Last year at the time of Diwali and post-Diwali Nov'2018 to Dec'2018, the ambient Air Quality Index (AQI) for the city was reported to be as high as 409 and 415 in the city, which surpassed the levels in Delhi at the same time. Delhi, reported to be the most polluted metro city, had a "poor" AQI of 281 on Chhoti Diwali that coincided with Kali Puja in Bengal. ${ }^{9}$ But it was still at a better spot than Kolkata's reading that time. Though on Diwali, Delhi notoriously topped the chart with an average AQI of 390 still it was postulated that the sustained high AQI of Kolkata over two days would possibly lead to worse adverse impact on health of the residents than the spike in Delhi on Diwali night. Also, due to the high density of population in Kolkata and relatively lower green cover (less than $5 \%$ of the city's area) more people will be exposed and the public health impact is quite worrisome for Kolkata residents more than Delhi residents. ${ }^{10}$

This year also post-Diwali the air quality dipped to poor category with $\mathrm{AQI}$ in the air monitoring stations of the city hovering around 200 to 300 . The city's AQI crossed the 301 marks (very poor) in Nov'2019, surpassing even that of Delhi's 275 at the same time, but then the cyclone Bulbul made some improvements by Heavy rain and gusty winds which cleared fine particulate matters from the city's air, improving its AQI to 'good' and 'satisfactory' from 'poor' and 'very poor'. ${ }^{11}$

\section{What are the Causes of Such Rapid Increase in Air Pollution?}

With the increase in number of vehicles on roads, industrialisation and lack of infrastructural facilities, the rise in pollution in the city has been enormous. A study on different sources of air pollution in Kolkata revealed that transportation is the leading contributor to air pollution in the city (51.4\%) followed by industrial pollution (24.5\%) and dust particles (21.1\%). ${ }^{12}$ Figure 3 compares current contributions and predicted future contributions in 2030 of various sources of air pollution in Kolkata.

Motor vehicles alone are the major cause of pollution in Kolkata. According to studies, over $95 \%$ of pollution has been found to be caused due to diesel-based vehicles and commercial vehicles. Most of the vehicles (private and commercial) plying in the city either use petrol or diesel as fuel. There are plenty of old vehicles which emit smoke and harmful gases; there is no pollution check done to these vehicles. Along with this, there are lots of public transport vehicles like autos, trams, open buses which are in poor condition. Apart from this these high number of vehicles-both personal and commercial-cause traffic and congestion, leading to more wastage of fuel, commuting time and increased levels of pollution. ${ }^{13}$ Apart from this, there are thermal power plants in and around the city which cause pollution both in air as well as water. ${ }^{12}$ There are also many small scale industries in the city area which are violating the pollution laws and making it difficult for people around them to breathe. 


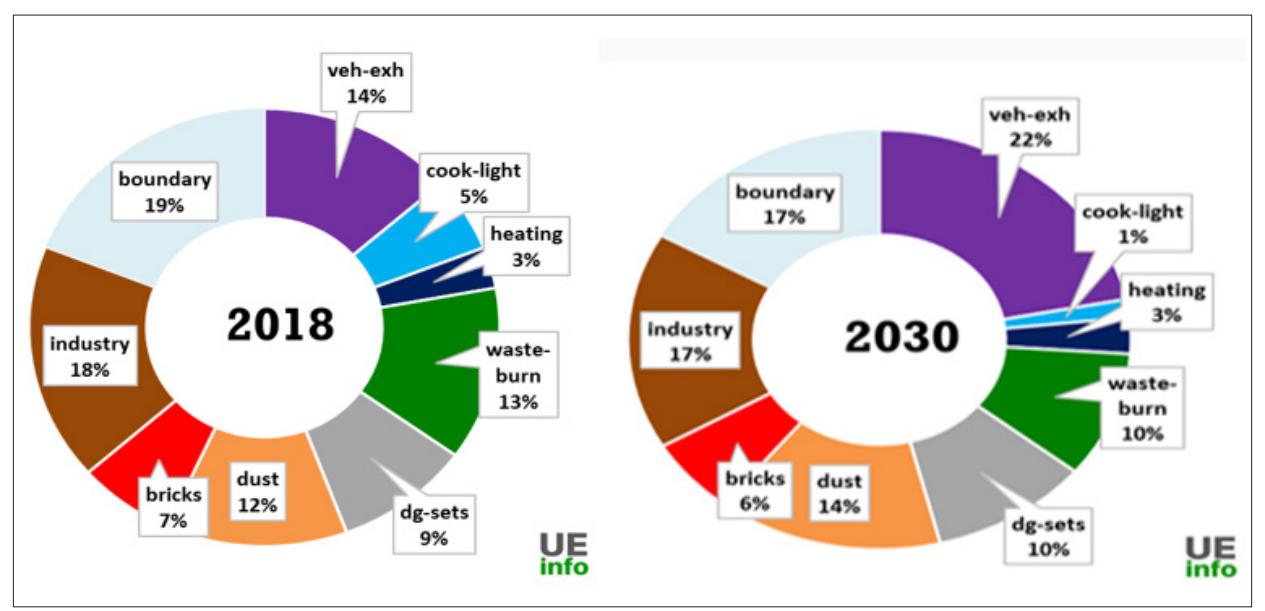

Figure 3.Predicted change in contributions from different sources in air pollution of Kolkata in year 2030 in comparison with year 2018 with the help of Chemical Transport Modelling

[Source: http://www.urbanemissions.info/india-apna/kolkata-india/]

Popularisation of stubble-burning in rural Bengal around winter months is also affecting the air quality much the same way crop burning in Punjab and Haryana is fouling up the air quality in Delhi. For the past few years, farmers in the adjoining districts of Hooghly, Nadia, North 24 Parganas and Howrah are taking stubble burning post-harvesting as a low-cost, easier and time-saving alternative. ${ }^{14}$ The emission is invading the city with wind blowing from northeast to southwest. Still unlike Delhi where the pollution has transboundary sources, Kolkata's pollution is mostly of its own.

Another important cause for air pollution in the city is ill management of waste. Open Trash burning is quite a common practice and is carried on a regular basis. There are huge dump yards where huge quantities of trash is being burned regularly, causing pollution in the air. Residents' region constantly bear the stench and acrid fumes being released by municipal dump yard in the area. ${ }^{15}$

Use of plastic is also one of the other issues in Kolkata causing pollution havoc. Although government made many attempts to ban the use of single-use plastic, the city has been rather slow in implementing the same. Many people use plastic bags daily and these plastic bags are either burnt or thrown in water. Burning plastic not only gives a bad smell, but also pollutes the air and emits harmful gasses. Similarly, an ill-equipped disposal system has ensured that a major chunk of the e-waste is crudely dismantled or burnt in a little over 1,000 informal units in the city and suburbs, exposing again millions to health hazards. ${ }^{16}$

At the same time, due to rapid urbanisation and unprecedented growth in population, many trees have been cut down and this has further deteriorated the quality of air in the atmosphere. With raising population and urbanisation, new buildings are being constructed leading to construction dust like cement, wood trash and the like. There is a temporal variation in source contributions and spatial contributions depending on meteorological factors also.

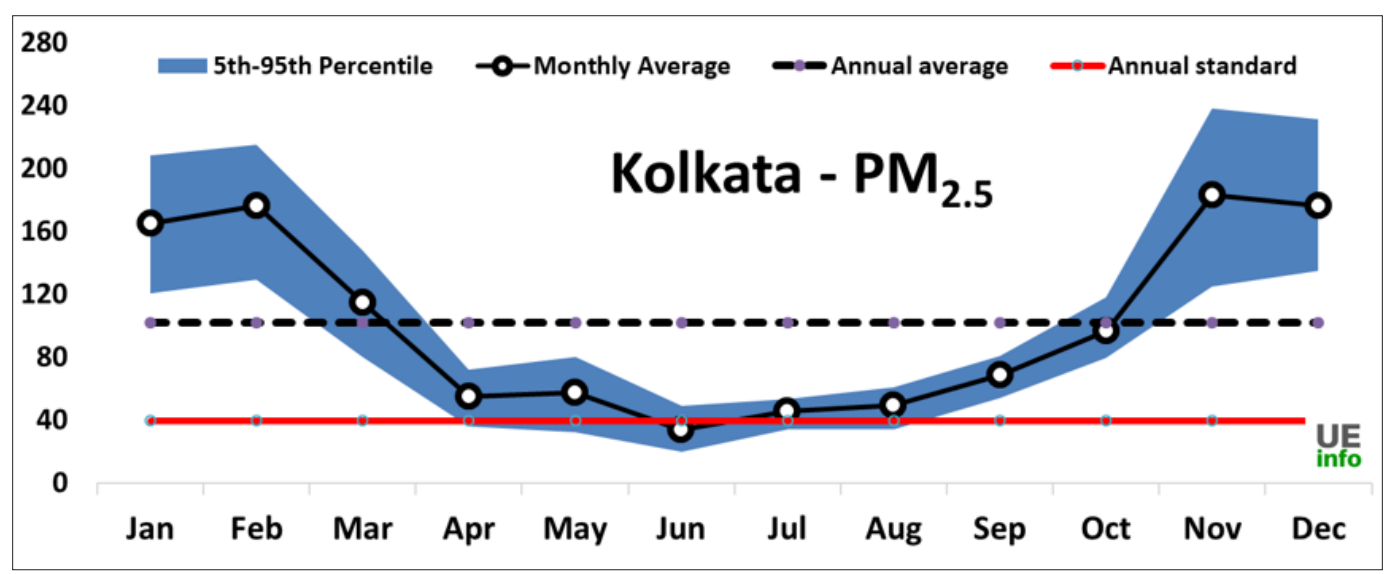

Figure 4.The ribbon graph shows the variation for average PM2.5 pollution by month

[Source:http://www.urbanemissions.info/india-apna/kolkata-india/] 
As Kolkata usually has a damp weather the dust particles get trapped easily. As the winter arrives, a slight dip in the temperature aggravates the situation with 'temperature inversion' leaving pollutants hanging low in the atmosphere as the vertical wind movement gets lowered. ${ }^{17}$ This makes air pollution an acute problem in the city during winters when the Air Quality index rises above 300/400. There is smog everywhere and situation is worst at the time of Diwali when firecrackers are burnt, people sit around fire burning wood to keep themselves warm. This causes increased smog and the whole city is covered with poor quality of air resulting in many health hazards. In the Figure 4 is a ribbon graph representing the monthly variations in PM 2.5 levels in Kolkata.

\section{How Air pollution is Affecting Health of Residents?}

Air pollution have myriads of health effects ranging from headache irritation in eyes, sneezing, cough, allergies body rashes and respiratory disorders to cancers. ${ }^{18}$ It has become the fifth independent risk factor for NCDs as per WHO. The smog is equal to smoking of 22 cigarettes on an average. A study by Chittaranjan National Cancer Institute $(\mathrm{CNCl})$, in collaboration with West Bengal Department of Environment and the Central Pollution Control Board ( $C P C B)$, has found that around $70 \%$ of people in the city of Kolkata suffer from respiratory disorders caused by air pollution. ${ }^{19}$ People who spend longer periods on roads like school-/college-going students, hawkers, drivers of public transport are amongst the worst affected and are easily falling prey to diseases like asthma and later COPD. The pollution is at peak during night time and early in the morning. People who exercise in the mornings inhale deeper and this leads to more penetration of bad air in their lungs. Resulting in children suffering from lung diseases as well as genetic aberrations in exposed lung tissues. ${ }^{20}$

It was reported that in the year 1995 almost 10,647 premature deaths were attributed to air pollution in the city. ${ }^{21,22}$ Another study has reported that almost $47 \%$ of Kolkata's population suffers from Lower Respiratory Tract Symptoms (LRTs) and the lungs of city residents are being seven times more burdened in comparison with their rural counterparts due to air pollution. ${ }^{23,24}$ It has been seen that the workers exposed to high levels of vehicular emission like traffic policemen, roadside hawkers, taxi and auto drivers suffer from the likes of respiratory diseases, haematological abnormalities, impaired liver function and even neurobehavioral problems possibly because of air pollution. ${ }^{19,25}$ Many people are also under risk of cancer because of air pollution. More deaths due to lung cancer and heart attacks are the major concern in the present era. Kolkata has been recently nicknamed as the "Iung cancer capital of India". ${ }^{26}$ As per the Global Burden of Disease Study (2017) city residents are losing 2 years from their average life expectancy owing to Air pollution. ${ }^{27}$

\section{Technological Measures to Curb air Pollution}

It is high time that the city takes serious measures to curb air pollution and stop genocide in the making. Presently the WBPCB is in process to set up a 31 more manual ambient airquality monitoring units across the state, 15 of which will be in different places in the city of Kolkata. Out of 31 stations, it is proposed that 25 will measure PM10. There will be only two PM2.5-Set 1 stations and four PM2.5-Set 2 stations. There are also efforts to establish five new automatic airquality monitoring in the city as per directions of $\mathrm{CPCB}$. According to recent development, manual ambient airquality monitor should be banned. Instead of deployment of 5,000 electric buses and full electrification the ferries on the Ganges River by $2030,{ }^{28}$ efforts should be made to have solar-operated vehicles and ferries.

While government is taking many steps to control pollution and its effects but the pace is really slow. Technology should be used to improvise public transport for frequency, speed, improved vehicle efficiency standards and comfort that will encourage wider usage of public transport leading to lesser vehicles on roads. Innovative approaches like carpooling should be encouraged by public and authorities to reduce number of vehicles on roads. Strict parking policies and efficient and cheap public transport would also refrain citizens from using their own vehicles. Redesigning the infrastructure such as roads and transport system to promote walking and cycling would help reduce traffic and congestion as well as the smoke emitting from vehicles. Also, unless the motorists switch to clean fuel like CNG or CBM from diesel and petrol, the condition is unlikely to improve. Modern technology should be used to check pollution from all the vehicles with strict measures and penalties for those not complying with rules. Cleaning of roads and other public places must be carried out regularly, this will stop from accumulation of dust particles. Waste burning and coal burning by street-side food vendors should be totally stopped and recycling should be promoted. Construction activities should be regulated and protective measures to ensure environment protection should be strictly adopted. Regular Monitoring of the existing thermal power plants which are in use would also help to great extent. Turning to more green energy generation and sensible utilisation is highly recommended. Government should also take active measures to spread awareness among public about effects of air pollution on their lives. This will help citizens to take initiatives to help save the environment and their future generations such as: Avoid going out when it is not necessary. Use of protective measures such as dust mask when government advisory is given.

However, exposure to air pollutants is largely beyond the 
control of individual and requires multi-sectoral approach by public authorities at the national, regional and international levels by engaging relevant sectors like transport, energy production, industry and health in the development and implementation of long-term policies to reduce the risks of air pollution to health.

\section{Conflict of Interest: None \\ References}

1. World Health Organization; Geneva: 2018. WHO global ambient air quality database. Available from: http:// www.who.int/airpollution/data/cities/en/ [Google Scholar].

2. Beig G, Chate DM, Ghude SD, Ali K, Satpute T, Sahu SK, Parkhi N, Trimbake HK. Evaluating population exposure to environmental pollutants during Deepavali fireworks displays using air quality measurements of the SAFAR network. Chemosphere 2013; 92(1): 116124. Available from: https://www.sciencedirect.com/ science/article/pii/S0045653513003512?via\%3Dihub [PubMed/ Google Scholar].

3. Census of India. Series 30. Director of Census Operation; West Bengal, Kolkata: 2011; 245-256. (Provisional Population Totals, West Bengal). [Google Scholar].

4. Centre for Science \& Environment, New Delhi, India. 2014. Energy and Buildings. Retrieved December 23, 2014; Available from: http://www.cseindiahttp://www. cseindia.org/userfiles/Energy-and-\%20buildings.pdf.

5. World Health Organization . Urban Air Pollution in Megacities of the World. World Health Organization; Geneva, Switzerland: 1992. [Google Scholar].

6. WHO Air quality guidelines for particulate matter, ozone, nitrogen dioxide and sulfur dioxide, Global update 2005, Summary of risk assessment. [last accessed on 2011 September 20]. Available from: http://whqlibdoc.who. int/hq/2006/WHO_SDE_PHE_OEH_06.02_eng.pdf .

7. West Bengal Pollution Control Board. Air Quality Management: Final Report. WBPCB in Collaboration with Asian Development Bank; Intercontinental Consultant and Technocrats Pvt. Ltd: New Delhi, India, 2005.

8. West Bengal Pollution Control Board. Annual Report 2008-2010; Government of West Bengal: Kolkata, India, 2010.

9. Basu J, Roy S. Calcutta Diwali air quality worst among metros. Last accessed on 2018 Jun 15. Available from: https://www.telegraphindia.com/states/west-bengal/ calcutta-diwali-air-quality-worst-among-metros/ cid/1674477.

10. You're breathing poison; Kolkata's air worse than Delhi's in Novembe. Available from: https://timesofindia. indiatimes.com/city/kolkata/youre-breathingpoison-kolkatas-air-worse-than-delhis-in-november/ articleshow/66823833.cms

11. Kolkata: Bulbul gone, AQI shoots up to 'very poor' level. Available from: https://timesofindia.indiatimes.com/ city/kolkata/bulbul-gone-aqi-shoots-up-to-very-poorlevel/articleshow/72248208.cms.

12. Ghose MK. Air pollution in the city of Kolkata: Health effects due to chronic exposure. Environmental Quality Management 2009; 19(2): 53-70. Available from: https://onlinelibrary.wiley.com/doi/abs/10.1002/ tqem.20245. [Google Scholar].

13. Spiroska J, Rahman MA, Pal S. In Air Pollution in Kolkata: An Analysis of Current Status and Interrelation between Different Factors. SEEU Review 2013; 8(1): 181-214. Available from: https://content.sciendo.com/view/ journals/seeur/8/1/article-p182.xml?lang=en [Google Scholar].

14. Bandyopadhyay N. 25,000 diesel-run commercial vehicles aged 10+ still ply in Kolkata. Available from: http:// timesofindia.indiatimes.com/articleshow/71929426. cms?utm_source=contentofinterest \&utm medium=text\&utm_campaign=cppst [Last accessed on 2019, Dec 14]

15. Bandyopadhyay K. Kolkata City air quality index shoots past 200 a week before Diwali. https:// timesofindia.indiatimes.com/city/kolkata/city-airquality-index-shoots-past-200-a-week-before-diwali/ articleshow/71696645.cms.

16. Karak T, Bhattacharyya P, Das T, Paul RK, Bezbaruah R. Non-segregated municipal solid waste in an open dumping ground: A potential contaminant in relation to environmental health. Int J Environ Sci Technol 2013; 10: 503-518. [DOI: 10.1007/s13762-013-0184-5/ CrossRef/ Google Scholar].

17. Joon V, Shahrawat R, Kapahi M. The Emerging Environmental and Public Health Problem of Electronic Waste in India. J Health Pollut 2017; 7(15): 1-7. Available from: https://www.journalhealthpollution.org/doi/ pdf/10.5696/2156-9614-7.15.1 [DOI: 10.5696/21569614-7.15.1/ PubMed/ Google Scholar].

18. Zhan D, Kwan MP, Zhang W, Wang S, Yu J. Spatiotemporal Variations and Driving Factors of Air Pollution in China. Int J Environ Res Public Health 2017; 14(12): 1538. [PubMed/ Google Scholar].

19. Ghorani-Azam A, Riahi-Zanjani B, Balali-Mood M. Effects of air pollution on human health and practical measures for prevention in Iran. J Res Med Sci 2016; 21: 65. DOI: 10.4103/1735-1995.189646. [PubMed/ Google Scholar].

20. Mukhopadhyay, K. Air Pollution in India and Its Impact on the Health of Different Income Groups; Nova Science Publishers, Inc.: New York, NY, USA, 2009.

21. Lahiri T, Roy S, Ganguly S, Ray MR, Lahiri P. Air pollution in Calcutta elicits adverse pulmonary reaction in 
children. Ind J Med Res 2000; 112: 21-26. [PubMed/ Goolge Scholar].

22. Ghose MK. Controlling of motor vehicle emissions for a sustainable city. TIDEE 2002; 1(2): 273-282. [Google Scholar/ ResearchGate].

23. Schwela W, Haq G, Huizenga C, Han W, Fabian H, Ajero M. Urban Air Pollution in Asian Cities Status, Challenges and Management; Earthscan Publishers: London, UK, 2006. Available from: https://www.crcpress.com/ Urban-Air-Pollution-in-Asian-Cities-Status-Challengesand-Management/Schwela-Haq-Huizenga-Han-FabianAjero/p/book/9781138986589.

24. Roy S, Ray MR, Basu C, Lahiri P, Lahiri T. Abundance of siderophages in sputum: Indicator of an adverse lung reaction to air pollution. Actayologica 2006; 45(6): 958-964. Available from: https://www.karger.com/ Article/Abstract/328371 [PubMed/ Google Scholar].

25. West Bengal Pollution Control Board. A Quinqueenniel Report, April 1998 to March 2003; West Bengal Pollution Control Board: Kolkata, India, 2003.

26. De S, Kushwah GDS, Dharwey D, Shanmugasundaram D. Respiratory Morbidity of Roadside Shopkeepers Exposed to Traffic-related Air Pollution in Bhopal, India. J Health Pollut 2019; 9(21): 190305. [DOI: 10.5696/2156-9614-9.21.190305/ PubMed/ Google Scholar].

27. Mondal S. City tops lung cancer find. [Last accessed on 2019 Dec 15]. Available from: https://www. telegraphindia.com/states/west-bengal/city-tops-lungcancer-find/cid/1189622.

28. India State-Level Disease Burden Initiative Air Pollution Collaborators. The impact of air pollution on deaths, disease burden, and life expectancy across the states of India: the Global Burden of Disease Study 2017. Lancet Planet Health 2019; 3(1): e26-e39. [DOI: 10.1016/ S2542-5196(18)30261-4/ PubMed/ Google Scholar].

29. Central Pollution Control Board (CPCB) Ministry of Environment. Forest and Climate Change. Government of India. CPCB; New Delhi: 2011. Air quality monitoring, emission inventory and source apportionment study for Indian cities-national summary report. Available from: http://cpcb.nic.in/displaypdf.php?id=RmluYWxOYXRpb25hbFN1bW1hcnkucGRm [Google Scholar]. 